\title{
SiGeC/Si superlattice microcoolers
}

\author{
Xiaofeng Fan, ${ }^{\text {a) }}$ Gehong Zeng, Chris LaBounty, and John E. Bowers \\ Department of Electrical and Computer Engineering, University of California, Santa Barbara, \\ California 93106 \\ Edward Croke \\ HRL Laboratories, LLC, Malibu, California 90265 \\ Channing C. Ahn \\ California Institute of Technology, Pasadena, California 91125 \\ Scott Huxtable and Arun Majumdar \\ Department of Mechanical Engineering, University of California, Berkeley, California 94720 \\ Ali Shakouri \\ Baskin School of Engineering, University of California, Santa Cruz, California 95064
}

(Received 8 November 2000; accepted for publication 24 January 2001)

\begin{abstract}
Monolithically integrated active cooling is an attractive way for thermal management and temperature stabilization of microelectronic and optoelectronic devices. SiGeC can be lattice matched to $\mathrm{Si}$ and is a promising material for integrated coolers. SiGeC/Si superlattice structures were grown on $\mathrm{Si}$ substrates by molecular beam epitaxy. Thermal conductivity was measured by the $3 \omega$ method. SiGeC/Si superlattice microcoolers with dimensions as small as $40 \times 40 \mu \mathrm{m}^{2}$ were fabricated and characterized. Cooling by as much as 2.8 and $6.9 \mathrm{~K}$ was measured at $25^{\circ} \mathrm{C}$ and $100^{\circ} \mathrm{C}$, respectively, corresponding to maximum spot cooling power densities on the order of 1000 W/cm² . (C) 2001 American Institute of Physics. [DOI: 10.1063/1.1356455]
\end{abstract}

Thermoelectric (TE) refrigeration in a solid-state active cooling method with high reliability. $\mathrm{Bi}_{2} \mathrm{Te}_{3}$-based TE coolers are widely used for cooling and temperature stabilization of microelectronic and optoelectronic devices, but their processing is a bulk technology and is incompatible with integrated circuit fabrication process. Solid-state coolers monolithically integrated with microelectronic and optoelectronic devices are an attractive way to achieve compact and efficient cooling. It can lower the cost of fabrication and packaging, and can selectively cool individual key devices instead of the whole chip. However, the thermoelectric figure of merit (ZT) is quite low for most of the semiconductors used in microelectronics and optoelectronics. This makes it difficult to get high cooling performance. Recently heterostructure thermionic and superlattice coolers have been proposed, and theoretical calculations show that large improvements in ZT can be achieved and efficient refrigeration becomes possible with coolers made of conventional semiconductor materials. ${ }^{1-8}$

More recently, a factor of seven enhancement of ZT relative to bulk $\mathrm{Si}$ was measured for a $\mathrm{Si} / \mathrm{Ge}$ superlattice. ${ }^{9}$ $\mathrm{SiGe} / \mathrm{Si}$ superlattice coolers have also been demonstrated with a maximum cooling of $7.2 \mathrm{~K}$ at $150{ }^{\circ} \mathrm{C} .{ }^{10,11}$ Due to the larger lattice constant of germanium compared to silicon (4.2\%), Ge and SiGe grown on silicon are compressively strained, thus buffer layers are required for thick $\mathrm{Si} / \mathrm{Ge}$ and $\mathrm{SiGe} / \mathrm{Si}$ superlattice layers. This increases the cost of material growth and the complexity of integration with Si-based devices. By adding a small amount of carbon into the SiGe material system, strain can be adjusted due to the small lat-

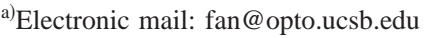

tice constant of carbon. By properly selecting the Ge and C ratio, $\mathrm{SiGeC}$ can be lattice matched to silicon, and thick $\mathrm{SiGeC}$ or $\mathrm{SiGeC} / \mathrm{Si}$ superlattice can be directly grown on $\mathrm{Si}$ without strain. Furthermore, while most of the band offset between $\mathrm{SiGeC}$ and $\mathrm{Si}$ lies in the valence band, its conduction band offset is larger than that between $\mathrm{SiGe}$ and $\mathrm{Si}^{12,13}$ This makes it possible to use thermionic emission to enhance the TE cooling for both $n$ - and $p$-type $\mathrm{SiGeC} / \mathrm{Si}$ materials. ${ }^{1-4}$ In this letter, we report the experimental results on $\mathrm{SiGeC} / \mathrm{Si}$ superlattice microcoolers. Superlattice structures can improve the cooler performance by reducing the thermal conductivity between the hot and the cold junctions ${ }^{14,15}$ and by selective emission of hot carriers above the barrier layers in the thermionic emission process. Si-based microelectronic devices can be monolithically integrated with these coolers to achieve better performance and reliability.

The $\mathrm{SiGeC/Si}$ superlattice sample was grown in a Perkin-Elmer Si molecular beam epitaxy (MBE) system capable of codepositing $\mathrm{Si}, \mathrm{Ge}$, and $\mathrm{C}$ onto $5 \mathrm{in}$. Si substrates. Solid $\mathrm{Si}, \mathrm{Ge}$, and $\mathrm{C}$ were evaporated through the use of e-beam sources controlled by electron impact emission sensors $(\mathrm{Si}, \mathrm{Ge})$ and by monitoring atomic mass unit $36\left(\mathrm{C}_{3}\right)$ with a quadrupole mass spectrometer (C). Prior to loading into the MBE system, $125 \mathrm{~mm}$ diameter, (001)-oriented $\mathrm{Si}$ substrate, doped to $<0.005 \Omega \mathrm{cm}$ with As, was stripped using $5 \%$ hydrogen fluoride. After rinsing with deionized water, the wafer was loaded in the MBE chamber. In order to remove any remaining oxide and to prepare the sample for epitaxial growth, the substrate was heated to $850{ }^{\circ} \mathrm{C}$ and exposed to a $0.1 \AA / \mathrm{s}$ Si flux for $30 \mathrm{~s}$.

The structure consisted of a $2 \mu \mathrm{m}$ thick $\mathrm{Si}_{0.89} \mathrm{Ge}_{0.10} \mathrm{C}_{0.01} / \mathrm{Si}$ superlattice (100 periods, each sublayer 


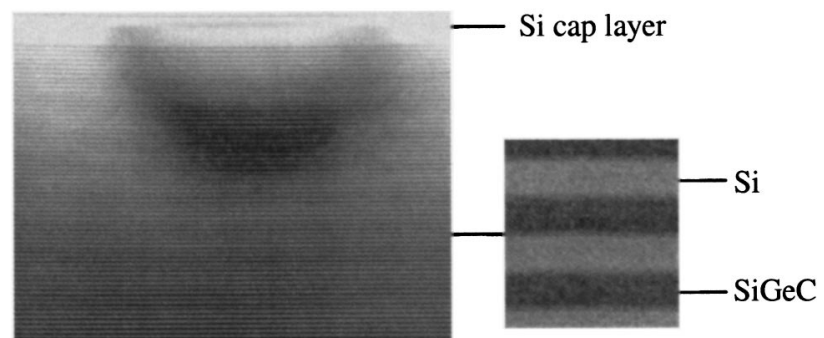

$\mathrm{SiGeC/Si} \mathrm{superlattice}$

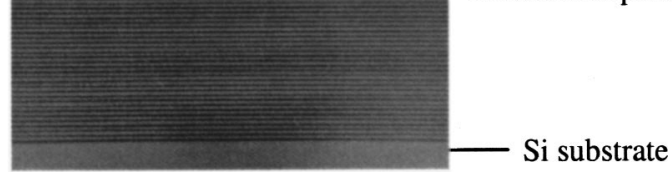

FIG. 1. Cross sectional transmission electron microscopy image of the MBE grown $\mathrm{SiGeC} / \mathrm{Si}$ superlattice cooler sample. The top is $100 \mathrm{~nm} \mathrm{Si} \mathrm{cap} \mathrm{layer;}$ the middle is $2 \mu \mathrm{m}$ superlattice of $100 \times\left(10 \mathrm{~nm} \mathrm{Si}_{0.89} \mathrm{Ge}_{0.10} \mathrm{C}_{0.01} / 10 \mathrm{~nm} \mathrm{Si}\right)$; the bottom is the Si substrate. An enlarged superlattice image is shown on the right-hand side.

$10 \mathrm{~nm}$ in thickness) grown at $500^{\circ} \mathrm{C}$, lattice matched to the $\mathrm{Si}$ substrate. The superlattice was doped with $\mathrm{Sb}$ to approximately $2 \times 10^{19} \mathrm{~cm}^{-3}$. Finally, the sample was capped with $100 \mathrm{~nm} \mathrm{Si}: \mathrm{Sb}$, grown at $460^{\circ} \mathrm{C}$ and doped to approximately $1 \times 10^{20} \mathrm{~cm}^{-3}$. A cross sectional transmission electron microscopy image of a grown $\mathrm{SiGeC} / \mathrm{Si}$ superlattice cooler sample is shown in Fig. 1.

The thermal conductivity is a key parameter for thermoelectric materials. The TE device performance increases with a decrease in thermal conductivity. Thin films and nanostructures have been used to reduce the thermal conductivity via acoustical phonon confinement and interface scattering. ${ }^{14-17}$ The $3 \omega$ method was used to measure the cross-plane thermal conductivity of the $\mathrm{Si}_{0.89} \mathrm{Ge}_{0.10} \mathrm{C}_{0.01} / \mathrm{Si}$ superlattice. ${ }^{18}$ The result is $0.085 \mathrm{~W} / \mathrm{cm} \mathrm{K}$, which is over one order lower than that of $\mathrm{Si}(1.5 \mathrm{~W} / \mathrm{cm} \mathrm{K})$.

The processing of $\mathrm{SiGeC} / \mathrm{Si}$ microcoolers is compatible with an integrated circuit fabrication process. The schematic diagram of the cooler device structure is shown in Fig. 2. Microcoolers were thermally isolated by dry etching mesa structures down to the $n^{+} \mathrm{Si}$ substrate. Metallization was made on the mesa and the Si substrate for cathode and anode contacts, respectively. The main part of the cooler structure is the $2 \mu \mathrm{m}$ thick superlattice. Its low electrical resistance requires low contact resistance for optimum device performance. ${ }^{19} \mathrm{Ti} / \mathrm{Al}$ metallization was used for ohmic contact. This was followed by annealing at $450{ }^{\circ} \mathrm{C}$ for $5 \mathrm{~s}$. Spe-

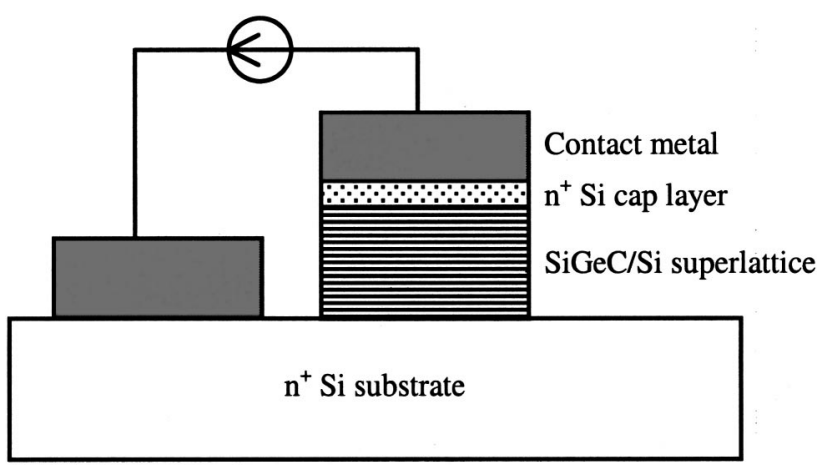
FIG. 2. Schematic diagram of SiGeC/Si microcoolers (not to scale). Where $\kappa$ and $d$ are the thermal conductivity and the thickness
Downloaded 03 Apr 2006 to 131.215 .225 .171 . Redistribution subject to AlP license or copyright, see http://apl.aip.org/apl/copyright.jsp

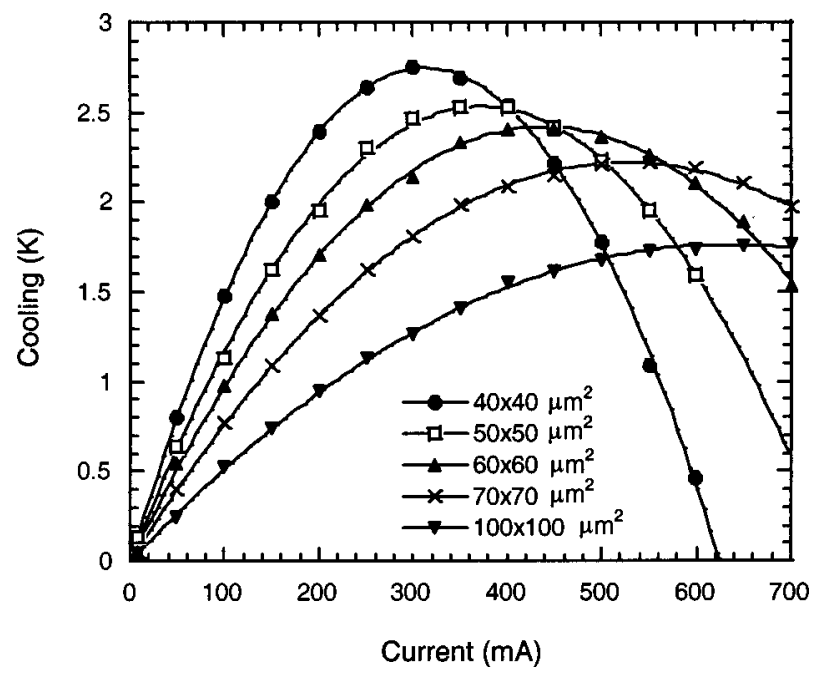

FIG. 3. Meaured cooling for various $\mathrm{SiGeC} / \mathrm{Si}$ cooler sizes at $25^{\circ} \mathrm{C}$ heat sink temperature. The cooler sizes are $40 \times 40 \mu \mathrm{m}^{2}, 50 \times 50 \mu \mathrm{m}^{2}, 60$ $\times 60 \mu \mathrm{m}^{2}, 70 \times 70 \mu \mathrm{m}^{2}$, and $100 \times 100 \mu \mathrm{m}^{2}$.

cific contact resistivity of $1.5 \times 10^{-7} \Omega \mathrm{cm}^{2}$ was measured by transfer length method.

$\mathrm{SiGeC/Si}$ superlattice microcoolers with various mesa sizes ranging from $40 \times 40$ to $100 \times 100 \mu \mathrm{m}^{2}$ were fabricated on one wafer. They were tested on a temperature-controlled heat sink, which was set at a constant temperature during device testing. Device cooling was measured with micro thermocouples on top of the device and was relative to the values at zero current. Figure 3 displays the measured cooling on top of the devices as a function of current with the heat sink at $25^{\circ} \mathrm{C}$. $2.8 \mathrm{~K}$ cooling was obtained for the $40 \times 40$ $\mu \mathrm{m}^{2}$ devices. The test results show that the maximum cooling temperature increases as the device size decreases. This cannot be explained with ideal thermoelectric or thermionic models, and is due to the three-dimensional nature of current and heat spreading in the substrate. The Si substrate of the cooler devices is $500 \mu \mathrm{m}$ thick and its thermal resistance for the micro devices is about inversely proportional to the square root of the device area. On the other hand, the thermal resistance of the $\mathrm{SiGeC/Si}$ superlattice layer is inversely proportional to the device area. This different size dependence makes the effect of the nonideal heat sink smaller for smaller size devices.

For comparison, Si microcoolers were fabricated on $n^{+}$ Si substrates with similar device structure and processing. The results of the $40 \times 40 \mu \mathrm{m}^{2} \mathrm{Si}$ devices are shown in Fig. 4 along with those of the $\mathrm{SiGeC/Si}$ superlattice coolers of the same size. Over three-fold improvement in maximum cooling is observed for $\mathrm{SiGeC/Si}$ superlattice coolers over $\mathrm{Si}$ ones.

$\mathrm{SiGe}$ is a good TE material for high temperature applications. ${ }^{20}$ The $\mathrm{SiGeC} / \mathrm{Si}$ microcoolers also show better performance at higher temperatures. Figure 5 shows the measured cooling for $50 \times 50 \mu \mathrm{m}^{2} \mathrm{SiGeC} / \mathrm{Si}$ microcoolers at various heat sink temperatures. The maximum cooling increases from $2.5 \mathrm{~K}$ at $25^{\circ} \mathrm{C}$ to $6.9 \mathrm{~K}$ at $100{ }^{\circ} \mathrm{C}$.

The maximum cooling power density is given by

$$
Q=\kappa\left(\Delta T_{\max }-\Delta T\right) / d,
$$




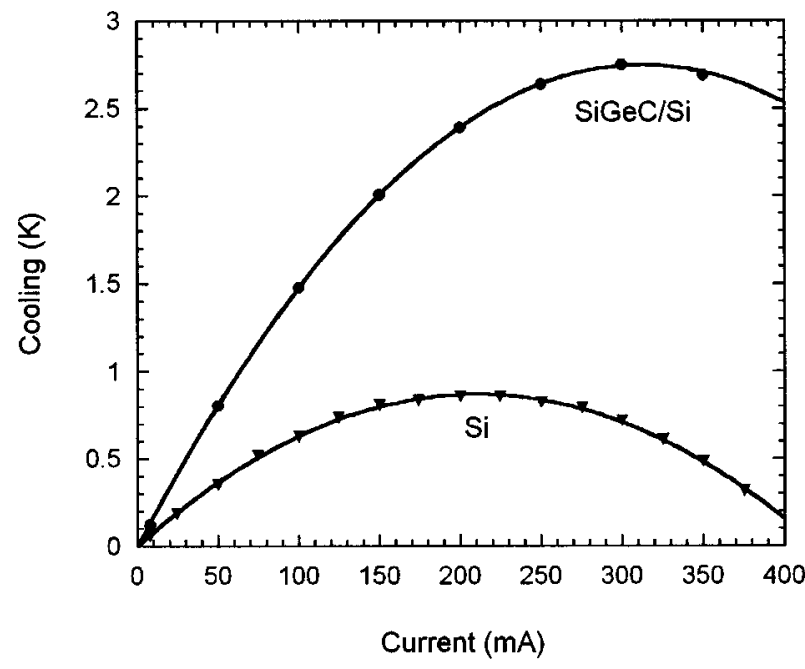

FIG. 4. Measured cooling for $40 \times 40 \mu \mathrm{m}^{2} \mathrm{SiGeC} / \mathrm{Si}$ and $\mathrm{Si}$ coolers at $25{ }^{\circ} \mathrm{C}$ heat sink temperature.

of the superlattice, while $\Delta T_{\max }$ and $\Delta T$ are the maximum and actual cooling temperature across the superlattice. At zero $\Delta T$, the coolers have the largest cooling power. Since the majority of the cooling happens over the $2 \mu \mathrm{m} \mathrm{SiGeC/Si}$ superlattice layer, several degrees of cooling corresponds to maximum cooling power densities on the order of 1000 $\mathrm{W} / \mathrm{cm}^{2}$ at zero temperature difference.

The maximum cooling temperature of the $\mathrm{SiGeC} / \mathrm{Si}$ superlattice microcoolers is limited by the contact resistance, Joule heating and heat conduction from the metal wire connected to the cold junction of the cooler, and the low ZT of the Si substrate. These can be solved by increasing the su-

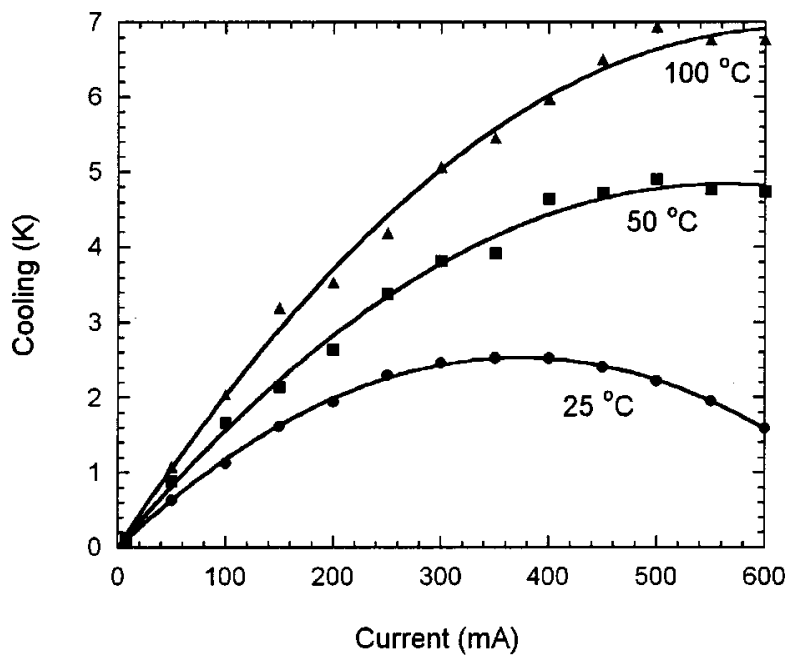

FIG. 5. Meausred cooling for $50 \times 50 \mu \mathrm{m}^{2} \mathrm{SiGeC} / \mathrm{Si}$ coolers at various heat sink temperatures. perlattice thickness, making $n$-type and $p$-type cooler arrays and substrate removal, respectively. Fundamentally, the cooler performance is determined by the TE ZT of the cooler materials. A superlattice gives more freedom in material engineering both electrically and thermally, and enables one to enhance the thermoelectric cooling by thermionic emission, ${ }^{1-4}$ quantum confinement, ${ }^{5,6}$ carrier pocket engineering, ${ }^{7,8}$ and phonon engineering. ${ }^{16,17}$ The structure and doping of the $\mathrm{SiGeC} / \mathrm{Si}$ superlattice studied here have not been optimized yet. With optimized material and device design and packaging, cooling up to tens of degrees is possible. Furthermore, $\mathrm{SiGeC} / \mathrm{Si}$ superlattices can be lattice matched to $\mathrm{Si}$, and $\mathrm{SiGeC} / \mathrm{Si}$ microcoolers can be monolithically integrated with Si-based devices to achieve compact and efficient localized cooling.

In summary, a lattice matched $\mathrm{SiGeC} / \mathrm{Si}$ superlattice was grown on $\mathrm{Si}$ by $\mathrm{MBE}$ and $\mathrm{SiGeC} / \mathrm{Si}$ superlattice microcoolers were demonstrated. Cooling by as much as 2.8 and $6.9 \mathrm{~K}$ was measured at heat sink temperatures of $25^{\circ} \mathrm{C}$ and $100^{\circ} \mathrm{C}$, respectively, corresponding to maximum cooling power densities on the order of $1000 \mathrm{~W} / \mathrm{cm}^{2}$.

This work is supported by DARPA HERETIC program and the Army Research Office.

${ }^{1}$ A. Shakouri and J. E. Bowers, Appl. Phys. Lett. 71, 1234 (1997).

${ }^{2}$ A. Shakouri, C. LaBounty, P. Abraham, J. Piprek, and J. E. Bowers, Mater. Res. Soc. Symp. Proc. 545, 449 (1999).

${ }^{3}$ G. D. Mahan and L. M. Woods, Phys. Rev. Lett. 80, 4016 (1998)

${ }^{4}$ C. B. Vining and G. C. Mahan, J. Appl. Phys. 86, 6852 (1999).

${ }^{5}$ L. D. Hicks and M. S. Dresselhaus, Phys. Rev. B 47, 12727 (1993).

${ }^{6}$ L. D. Hicks, T. C. Harman, and M. S. Dresselhaus, Appl. Phys. Lett. 63, 3230 (1993).

${ }^{7}$ T. Koga, X. Sun, S. B. Cronin, and M. S. Dresselhaus, Appl. Phys. Lett. 73, 2950 (1998).

${ }^{8}$ T. Koga, X. Sun, S. B. Cronin, and M. S. Dresselhaus, Appl. Phys. Lett. 75, 2438 (1999).

${ }^{9}$ T. Koga, S. B. Cronin, and M. S. Dresselhaus, Appl. Phys. Lett. 77, 1490 (2000).

${ }^{10}$ X. Fan, G. Zeng, E. Croke, G. Robinson, C. LaBounty, A. Shakouri, and J. E. Bowers, Phys. Low-Dimens. Semicond. Struct. 5, 1 (2000).

${ }^{11}$ G. Zeng, A. Shakouri, C. LaBounty, G. Robinson, E. Croke, P. Abraham, X. Fan, H. Reese, and J. E. Bowers, Electron. Lett. 35, 2146 (1999).

${ }^{12}$ H. J. Osten, J. Appl. Phys. 84, 2716 (1998).

${ }^{13}$ B. L. Stein, E. T. Yu, E. T. Croke, A. T. Hunter, T. Laursen, A. E. Bair, J. W. Mayer, and C. C. Ahn, Appl. Phys. Lett. 70, 3413 (1997).

${ }^{14}$ S. M. Lee, D. G. Cahill, and R. Venkatasubramanian, Appl. Phys. Lett. 70, 2957 (1997).

${ }^{15}$ R. Venkatasubramanian, Phys. Rev. B 61, 3091 (2000).

${ }^{16}$ A. Balandin, A. Khitun, J. L. Liu, K. L. Wang, T. Borca-Tasciuc, and G. Chen, in The 18th International Conference on Thermoelectrics: ICT Symposia Proceedings, Baltimore, Maryland, 29 August-2 September 1999, p. 189.

${ }^{17}$ G. Chen, T. Zeng, T. Borca-Tasciuc, and D. Song, Mater. Sci. Eng., A 292, 155 (2000)

${ }^{18}$ D. G. Cahill, Rev. Sci. Instrum. 61, 802 (1990).

${ }^{19}$ C. LaBounty, A. Shakouri, G. Robinson, P. Abraham, and J. E. Bowers, in The 18th International Conference on Thermodynamics: ICT Symposia Proceedings, Baltimore, Maryland, 29 August-2 September 1999, p. 23.

${ }^{20}$ C. B. Vining, J. Appl. Phys. 69, 331 (1991). 